\title{
Duchamp's Erotic Stereoscopic Exercises ${ }^{1}$
}

\section{Gavin Adams ${ }^{2}$}

ABSTRACT: This article explores certain links between medicine and art, with regard to their use of stereoscopy. I highlight a work by the artist Marcel Duchamp (the ready-made Stéréoscopie a la Main) and stereoscopic cards used in ophthalmic medicine. Both instances involve the drawing of graphic marks over previously existing stereoscopic cards. This similarity between Stéréoscopie a la Main and stereoscopic cards is echoed in the form of "stereoscopic exercises." Stereoscopic exercises were prescribed by doctors to be performed with the stereoscope as early as 1864 . Stereoscopic cards were widely diffused in the 19th century, often promoted as "stay-athome travel." It was over such kinds of materials that both Marcel Duchamp and doctors of ophthalmic medicine drew their graphic marks. I explore Duchamp's Stéréoscopie a la Main as a hypothetical basis for stereoscopic exercises of different types, proposing that this rectified ready-made is the locus for erotic stereoscopic exercises.

KEYWORDS: Art. Medicine. Duchamp. Stereoscope. Stéréoscopie a la Main. Ready-made.

RESUMO: Este artigo busca explorar certos elos entre a medicina e a arte por meio da estereoscopia. Destaca-se uma obra do artista Marcel Duchamp (o ready-made Stéréoscopie a la Main) e cartões estereoscópicos usados na oftalmologia. As duas instâncias envolvem o desenho de marcas gráficas sobre cartões estereoscópicos pré-existentes. A similaridade entre Stéréoscopie a la Main e os ditos cartões ecoa também na forma dos exercícios estereoscópicos. O cartão estereoscópico foi amplamente difundido na segunda metade do séc. XIX, frequentemente na forma da "viagem sem sair de casa." Foi sobre esse tipo de material que tanto médicos quanto Marcel Duchamp desenharam suas marcas. Explora-se a obra Stéréoscopie a la Main como um sítio hipotético para uma espécie de exercício, propondo que tal ready-made retificado seja um lugar para exercícios estereoscópicos eróticos.

PALAVRAS-CHAVE: Arte. Medicina. Duchamp. Estereoscopia. Stéréoscopie a la Main. Ready-made.
1. This article is the result of research carried out as part of CAPES' PNPD program, developed as post-doctoral studies under the supervision of Professor Thomás Santoro Haddad.

2. Post-doctoral researcher at Escola de Artes, Comunicação e Humanidades at the University of São Paulo (EACH-USP), São Paulo. Email:<gavadams@hotmail. com>. 
3. See Rosalind Krauss, (1993, p. 135)

4. See Octavio Paz, (1989, p. 31). Translations by the author.
Indeed the devices that Duchamp fashioned to pursue his interest

[in Precision Optics] look uncannily like illustrations from a book on psychophysiological research ${ }^{3}$.

The artist, Marcel Duchamp is associated with the notion of the readymade. Some of his signature works are precisely of that type (such as the famous urinal titled Fountain). Ready-mades are anonymous ordinary objects that are converted into works of art by the gratuitous gesture of the artist, thus dissolving the notion of "object of art." Contradiction is the essence of the gesture ${ }^{4}$. With his ready-mades, Duchamp sought to make it difficult to define art at all, as he moved away from painting. However, in some cases, the artist may intervene in the physical body of the readymades, slightly modifying or "rectifying" them; the modifications are generally of an ironic intent and tend to hinder any confusion between them and artistic objects.

This is the case with the ready-made that I wish to highlight: Stéréoscopie a la Main (1918), in which Duchamp drew geometric solids over a pair of existing stereoscopic photographs.

This text aims to contrast Duchamp's mark-making with a similar practice in another field altogether:, ophthalmologist doctors were drawing over stereoscopic photographs as early as 1912 in search of diagnostic and therapeutic results in the field of binocular vision, especially in the treatment of conditions such as strabismus.

The formal similarity between Stéréoscopie a la Main and certain stereoscopic cards for ophthalmologic use suggest links that may be interesting to explore (see Figures 1 and 2). The study of stereoscopy in the oeuvre of Marcel Duchamp may throw light on his Precision Optics; on the other hand, Duchamp's use of stereoscopy may explain on how a new kind of observer was made possible by a homogenization between different fields; that is, the stereoscopic field linking mass entertainment with the description of optical conditions such as strabismus. Conversely, the work of Duchamp highlights how the very instruments used for disciplining could also be a locus of resistance, and of the anarchic appropriation of elements meant for medical use.

The central concept that links Duchamp to ophthalmology is ocular movement, guided and disciplined by the stereoscope. Such bodily movement is present in diverse but related ways in the two fields. On one hand, ocular movement is one of the processes of normalizing and disciplining the human body around an optical device through medicinal practice; on the other hand, it also plays a more anarchic role in Duchampian erotic gymnastics.

In the field of ophthalmology, ocular movements must follow prescribed lines when practiced in the doctor's consulting room or at home, supported by diagrams, geometric forms, and photographs, which seek to develop the patient's nervous and muscular systems by means of the controlled use of the stereoscope (see Figures 4 and 6). On the other hand, from the Duchampian perspective, the stereoscope serves as a machine where the eye glides along trajectories traced within visual mechanics, also expressed in works such as the Large Glass and the Rotoreliefs. 


\section{viv. $5,5-7,0$}
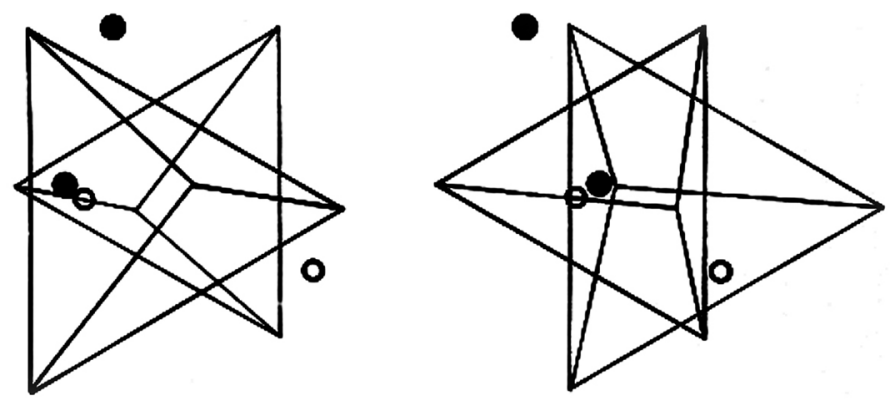

Figure 1 - Card VIII. Stereoscopic card for ophthalmologic use published by Hamblin, no date. Science Museum, London.

IX. 12
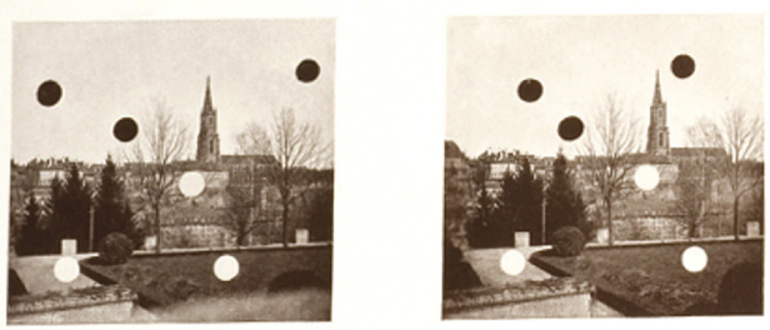

Figure 2 - Card IX. Stereoscopic card for ophthalmologic use published by Hamblin, no date. Science Museum, London.

The aim of this text is to underline the similarities between stereoscopic activity in the psychophysiology of vision and Duchamp's interest in stereoscopy, by comparing Stéréoscopie a la Main and a selection of stereoscopic cards for ophthalmologic use. The cards, in an unusual way, bring together the elements of both functions that I seek to highlight.

Vision and touch

There is a very special association between binocular movements and the expansion of gaze toward touch in stereoscopic viewing. This association is expressed as "tangibility." 
5. See Oliver Wendell Holmes, (1864, p. 124)

6. See Albert Underwood, (1909, p. 25).

7. See Rosalind Krauss, (1982, p. 138).

8. See Geoffrey Batchen, (1991, p. 3).
Tangibility is one of the most remarkable features of stereoscopic viewing, and has been observed since the invention of the stereoscope in 1833. Stereoscopic gazing involves a very particular engagement of the eyes, in which the sensation of "touch" is intensified in the ensuing visual operation. It is as if the eyes touch the object observed, "caressing" the scene gazed at. Added to the photographic detail, stereoscopic viewing was largely described in the terms of an inexhaustible visual experience. The American author Oliver Wendell Holmes, an enthusiast of the possibilities offered by the stereoscope, wrote an essay, "The Stereoscope and the Stereograph," on the recent invention, bringing its tactile sensations to the attention of the reader:

By means of these two different views of an object, the mind, as it were, feels round it and gets an idea of its solidity. We clasp an object with our eyes, as with our arms, or with our hands, or with our thumb and finger, and then we know it to be something more than a surface ${ }^{5}$.

Albert Underwood, founder of the stereoscopic company Underwood and Underwood (the main publisher of stereographs in America and Britain from 1880 to 1920), stated the following:

By means of these two different views of an object, the mind, as it were, feels around it and gets an idea of its solidity ${ }^{\circ}$.

This power to see "around" objects, allied to the feeling of penetrating the three-dimensional image, breaks up the relation of separation between the observing subject and observed object. Rosalind Krauss described the experience of stereoscopic viewing, highlighting the entry into the "deep channel of space," and pointing out how the movements of the eyes and those of the body are rendered synonymous:

These micro-muscular efforts are the kinesthetic counterpart to the sheerly optical illusion of the stereograph. They are a kind of enactment, on a very reduced scale, of what happens when a deep channel of space is opened before one. The actual adjustment of the eyes from plane to plane within the stereoscopic field is the representation by one part of the body of what another part of the body would do in passing through real space ${ }^{7}$.

Along the lines of Krauss' thinking, one could say that the expansion of the gaze toward touch propitiated by stereoscopic viewing allows for the re-staging of the eye as a member that touches the observed scene.

Geoffrey Batchen emphasizes the double movement of stereoscopic viewing, which he describes in the following paragraph:

Cut off from all distractions by the masked instrument held to the face, the eye of the viewer is dismembered from his or her immobilized body and induced to wander freely through the receding picture planes that unfold ahead. That same wandering eye simultaneously becomes a miniature prosthesis for another body; the viewer enjoys, as [Oliver Wendell] Holmes points out, the palpable sensation of turning into a flying phantom limb and thereby becoming an integral part of the representation being seen ${ }^{8}$. 
The observer becomes a "phantom limb" that travels in the scene observed, as a member manifested in the correlation between binocular movement and the haptic element of stereoscopic gazing. More specifically, this provides a connection between stereopsis and desire.

Binocular vision and stereopsis

Despite it being obvious that human vision involves the use of two eyes and that they capture different images, it was only in 1833 that Charles Wheatstone irrevocably demonstrated that the feeling of volume and depth that we experience as we look at the world is created by the difference in the images obtained by each eye when synthesized by the brain. This synthesis is called "stereopsis." The experiment that consolidated this discovery involved a device designed by him: the stereoscope. The apparatus isolated each of the images presented exclusively before each corresponding eye. Differences in the images produce stereopsis, while identical images do not propitiate this result.

In the 1900s, the scientist Helmholtz stated:

We therefore learn that two distinct sensations are transmitted from the eyes, and reach consciousness at the same time and without coalescing; that accordingly the combination of these two sensations into a single perceptual picture of the external world is not produced by any anatomical mechanism of sensation, but by a mental act?

However, in 1861, Oliver Wendell Holmes developed a version of the stereoscope that used lenses instead of mirrors for the visualization of the stereoscopic pair of images mounted on a card. The device was a commercial success, and with it many people visualized images in relief, published in millions in the following decades. This model became the standard viewing device in the massification of stereoscopic viewing up until the end of and beyond the 20th century. The typical environment for stereoscopic viewing was the bourgeois parlor, where the stereoscopic card collection and stereoscope shared space with the family's photograph album, and both were mobilized in the domestic rituals of social visiting ${ }^{10}$.

Wheatstone's stereoscope preceded photography lthe first recorded images were drawings), but the massive popularity of stereoscopy was achieved in association with the photographic image. Cards or glass plates bearing stereoscopic photographic pairs were published in great numbers from 1851 until the beginning of the 20th century, when they took up other forms of diffusion and use.

By the end of the 19th century, successful stereoscopic companies sent teams of photographers around the world to take three-dimensional images for their collections. A part of this production was published in thematic series, typically in an educational mode; they were aimed toward the emerging middle classes in the form of "stay-at-home travel," a kind of emulation of the didactic experience of the aristocratic Grand Tour.
9. See Hermann Helmholtz, (1885, p. 299-300).

10. See Beth Rayfield, (1998).The author highlights how stereoscopic viewing allowed for erotic exchanges in the context of the bourgeois parlor. 
11. See Shelley Rubin, (1992, pp. 2-3)

12. See Robert DeLeskie, (2000, pp. 63-64)

13. See Jib Fowles, (1994, p. 91)

14. See Robert DeLeskie, (2000, pp. 64-65)

15. Ibidem, (p. 98)

16. See Foster Rhea Dulles, (1964, pp. 107)
Keystone View was one of such companies. At the beginning of the 20th century, Keystone had acquired the stereoscopic collections of its rivals (such as Underwood \& Underwood and Kilburn), amassing millions of stereoscopic negatives. Keystone also published its own "stay-athome travel" sets, in which vistas from different parts of the world were presented as itineraries or thematic sets that emulated a real trip. Sometimes, these "travels" were accompanied by maps, where the points from which the photographs had been taken from were detailed; similar to some of Underwood \& Underwood's sets. These sets were often bound like books, so that they could sit alongside works of literature at home.

Self-improvement was a strong element in the lives of the 19th century's industrial bourgeoisie. To educate oneself, to make oneself in the world was part of the set of ideals valued by the emerging classes. Joan Shelley Rubin remarks on American society: "the democratization of property ownership and the rise of republicanism enhanced the prospect that Americans of more modest means could attain the respectability formerly limited to the aristocracy" ${ }^{\prime 1}$. The decrease in illiteracy, the weakening of traditional teaching strictures, and of domestic training in the Western world, caused the issuing of practical instructions in printed form to grow, to the detriment of oral transmission.

Deleskie ${ }^{12}$ points out that during the second half of the 19th century, highly respected figures such as Ralph Waldo Emerson promoted and supported the cause of self-culture. In many cases they even produced or endorsed selfimprovement texts or anthologies themselves, while "self-help" publications proliferated in a more populist vein. As a means of acquiring culture, these texts frequently enhanced the visual-based experience.

Stereoscopic viewing was seen by American consumers as a means to self-improvement. "The initial impetus behind stereoscopic viewing was, for many [in America], the staunchly Protestant one of self-betterment through learning. [...] The person who gained visual familiarity with things distant was more learned and thus a better candidate for success"13. Deleskie ${ }^{14}$ states that Underwood land competitors with similar material) clearly saw and positioned its stereo tours within the discourse of self-culture. Underwood even published its own self-improvement text, entitled The Stereograh and the Stereoscope: What they mean for individual development, what they promise for the spread of civilisation (1909). "Stereo tours can be understood as providing middle-class consumers with a means of acquiring the cultural capital linked to the burgeoning activity of tourism"15.

The European Grand Tour originated in the 16th century as the completion of a nobleman's education. The bourgeoisie adopted the Grand Tour and changed the face of tourism. By the mid-19th century, tourism had been greatly commodified. However, at the same time, the success of the organized tour and the tourist guidebook led to a homogenization of the travel experience. Packaged tours meant travelers were going to the same places more than ever, seeing the same sights, and crowding the same resorts ${ }^{16}$. As organized tours gained popularity, as suggested Karen Beth Brown, the focus of the travels clearly "shifted from open- 
ended exploration to circumscribed activity"17. Stereo tours of the "stay-at-home travel" type easily fitted into the format of the guided tour.

Circulating in the parlors of Europe and North America, stereoscopic cards offered middle-class viewers an unprecedented wealth of visual information about the foreign visible world. In the period before postcards or amateur handheld cameras (such as the Kodak Brownie), stereographs were probably the single most important kind of pictorial tourist souvenirs ${ }^{18}$. For those compelled to stay at home, the "armchair travelers" stereoscopic cards also provided an important alternate form of travel. According to Richard Altick, representational stand-ins for actual travels such as the panorama and the diorama became popular in Europe in the late 18th century, when the French Revolution and the Napoleonic Wars disrupted the Grand Tour on much of the continent" ${ }^{19}$. The stereograph clearly belonged to the tradition of representational substitutes. He states that "The stereoscope was the cosmorama and the panorama finally domesticated." Stereography presented a serious competition to earlier forms of travel-based entertainment.

Stereoscopy and pornography

Another important mode of consumption of stereoscopic images arose in the context of pornography. Although it is difficult to calculate exactly how many obscene stereoscopic images were produced in the 19th century, we know that with the appearance of the stereoscope a "flourishing clandestine industry" developed to produce and circulate erotic images: in relief, in daguerreotypes, and in glass and paper formats; all aimed toward male audiences ${ }^{20}$. This kind of pornographic stereoscopic production, no longer necessarily clandestine, continues to this day ${ }^{21}$. The content ranged from nudes in conventional art poses to the explicit sexual act ${ }^{22}$. Pornography seems to be an especially apt theme for the stereoscope, since the stereoscopic effect involves a feeling of physical touch operating through the gaze, a true "mass form of ocular possession" 23 .

Pellerin reports journalist Ernest Lacan's description of a stereoscopic daguerreotype of erotic character in 1853:

Stretch your hand and touch her silky dress. [...] And what about that lace whose transparent folds provide a glimpse of her rounded arm, does it not seem as if you are about to crush it beneath your fingers? And can you not see the daylight passing between the pearls of her necklace and the delicate skin of her neck? And what about the shadow of her lashes over her clear blue eyes, and the faint smile hovering about her lips? And can you not see the blood moving beneath her downy cheeks, the force which brings her soft, translucent skin to life?22.

In stereoscopic pornography, there is an explicit confluence of binocular movements and desire, suggesting that the act of stereoscopic viewing may have a sensual quality of possession, of touch, and an actively desiring gaze. Stereoscopic viewing offers a haptic invasion of the observed object, a visual-tactile landscape full of binocular exploration.
17. See Karen Beth Brown, (1992, p. 81)

18. See Peter Osborne, (2000, p. 19)

19. See Richard Altick, (1978, p. 180)

20. See Denis Pellerin, (2000, p. 91)

21. One could try to search the internet, combining the keywords stereoscopic and sex.

22. See William C Darrah, (1977, p. 158)

23. See Jonathan Crary, (1998, p. 127)

24. See Pellerin, (2000, p. 94) 
25. See Émile Javal, (1896, pp. 112-141)

26. See David Washburn Wells, (1912, p. 26)

27. See David Washburn Wells (1912, p. 65) and Émile Javal (1896, p. 112)

28. See David Washburn Wells, (1912, p. 41)
The stereoscope in ophthalmological practice

Late in the 19th century (1896), the French scientist Louis Émile Javal suggested the use of the stereoscope in the diagnosis and treatment of strabismus ${ }^{25}$. Javal brought out his great work Manuel du Strabisme [in 1896 and] seems to have been the first to adapt the principle of the stereoscope to latent strabismus, or heterophoria ${ }^{26}$. German scientist Edmund Landolt and the renowned American doctor D. W. Wells followed the same procedure, at least from 1868 (The Refraction and Accommodation of the Eye and Their Anomalies) and from 1912 (Stereoscopic Treatment of Heterophoria and Heterotropia), respectively. In 1904, Wells had previously published a selection of stereoscopic cards for medical use, in which "rectified" stereographs were likely to have been included. Nonetheless, in the 1912 title, Dr. Wells explicitly suggests the use of "rectified" stereoscopic photographs, that is, photographic images with added graphic marks (see Figure 3).

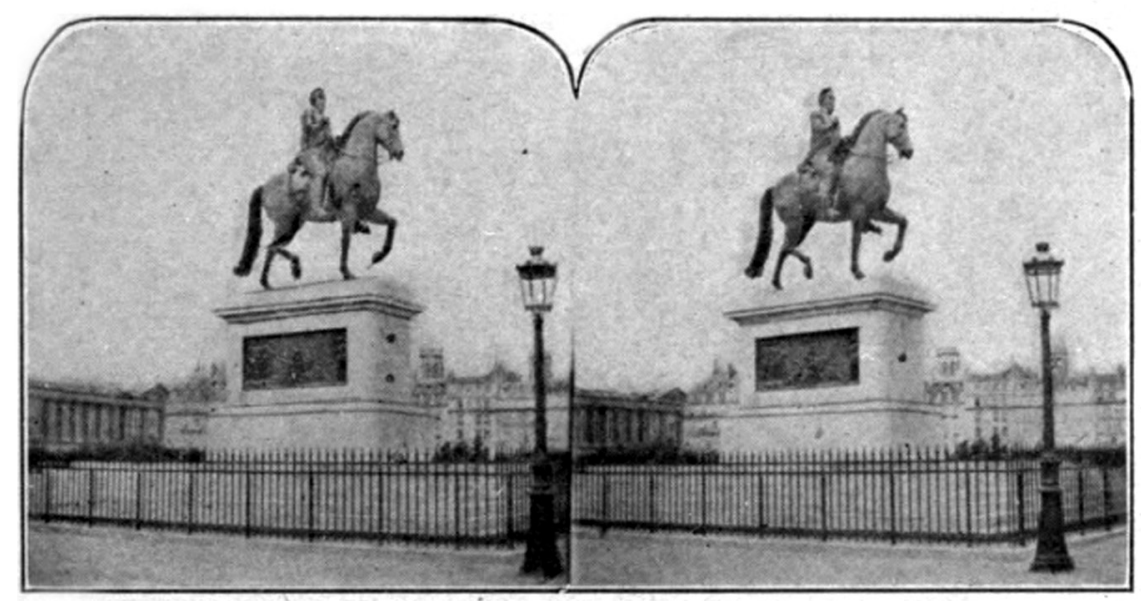

Fig. 15.-Showing Dots Marked on Stereograph.

Figure 3 - Illustration printed in Dr. Wells' book, Stereoscopic Treatment of Heterophoria and Heterotropia, 1912. New York: EB Meyrowitz.

The domestic Holmes-Bates stereoscope, the vehicle for "stay-athome" travel, found use in doctors' consulting rooms. Eventually, technical apparatus of a more complex nature were built based on the Bate-Holmes basic design. But the domestic stereoscope, widespread and easily accessible in Europe and the U.S., served as a basic platform for ophthalmologic activity, both at the doctor's premises and in the home. In particular, it enabled what the medical bibliography called "stereoscopic exercises" 27.

The patient is required to buy a Holmes' stereoscope with clips for inserting extra prisms, and a set of the Wells stereoscopic charts. It is important that the patient own these, as he is expected to use them occasionally for some months, to ensure his retaining his newly acquired faculty. These charts are not to be used indiscriminately, but in accordance with very exact instructions ${ }^{28}$. 
In cases where it was believed that deviations of sight were corrigible by the specific action of muscles attached to the ocular globe, the controlled repetition of certain eye movements was prescribed, so as to strengthen specific positions. These movements were supported and guided by graphic marks visualized through the stereoscope. Thus, diagnosis and exercises conducted through stereoscopic apparatus have become part of the psychophysiology of vision, developed from at least as early as 1868. Stereoscopic exercises using the stereoscope were explicitly prescribed by Javal (1868), Landolt (1886), and Wells (1912). Wells underlines that the aim of the exercise is not to develop only muscles, but also the nervous system, as it is the brain that is being trained: "The pianist makes his fingers educate his brain that the brain may do better work with the fingers" 29

Commercial stereoscopic photographs were used by doctors because the conditions for stereoscopic viewing and its procedures were already accepted within general knowledge and practice, having filtered throughout American and European societies.

\begin{abstract}
Many years ago Landolt suggested the use of the ordinary stereoscopic [photographic] pictures, putting two dots on one picture and a third dot on the other, so that the three will appear in a vertical line in the fused image. For homework after the patient has ceased his regular visits, two or three dozen of such photos, selected by him, are marked in this way, the dots being made as small as possible. He is thus taught to appreciate the absolute reproduction of natural scenery, and is constantly able to verify his binocular perception by a glance at the dots ${ }^{30}$.
\end{abstract}

Initially, before the use of photographic stereoscopic images, graphic marks for medical use were first drawn on their own on blank cards in order to isolate certain types of effect for diagnostic and therapeutic activities, but practice seems to have revealed difficulties in the visualization of the marks on the card. Lines and dots "floating" on their own on the cards seemed insufficient to allow the eyes to "grab" and comfortably fix the image. This fixing is necessary to stabilize the gaze for the operation at hand; that is, the interpretation of specific visual configurations. As the stereoscopic gaze at large had already been trained in the viewing of commercial stereoscopic photographs, the two forms were combined by drawing graphic marks over the existing photographs: the generic photographic image contained and helped the specific graphic mark to carry out its diagnostic or therapeutic function, as it provided a familiar visual field where the patient could carry out and hold stereopsis, which was the aim of the "stereoscopic exercises." The doctor observed the data obtained in the graphic markers las related orally by the patient) and evaluated the condition of the viewer-patient. "He [the patient] is thus taught to appreciate the absolute reproduction of natural scenery, and is constantly able to verify his binocular perception by a glance at the dots" ${ }^{\prime 31}$.

In this sense, drawn geometric solids were also mobilized (see Figure 4) in order to provide a stable basis for stereopsis, because they were easy to fuse, i.e., such solids were deemed to more promptly induce and hold stereopsis: "Instead of lines we may use geometrical figures representing solids of some simple form. Stereoscopic fusion is then facilitated by the tendency to a perception of the relief ${ }^{\prime \prime 2}$.
29. Ibidem, p. 72

30. Ibidem, pp. 45-46

31. Ibidem, p. 45

32. See Edmund Landolt, (1886, p. 410) 
33. Incidentally, in 1930 , Duchamp bought the book Geometrie Anaglyphique, by Henri Vuibert, first edition of 1921

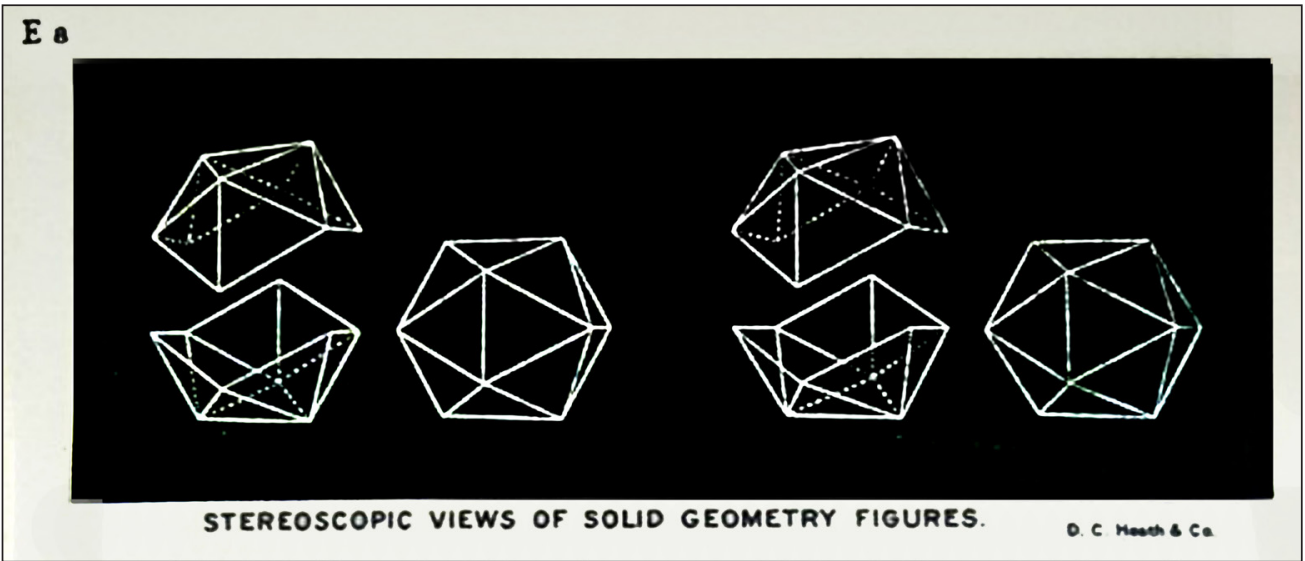

Figure 4 - Card E9. From the Eye Comfort Series, designed by Keystone view, published by Dr. D. W. Wells, no date. Private collection.

The use of a geometric solid, on its own or placed over a stereoscopic photograph, thus helped patients in their exercises and also helped in the detection of "suppression." Stereoscopic cards bearing geometric solids were also published in geometric mathematical sets, and some can be found amongst the cards used by doctors (see Figure 5$)^{33}$.

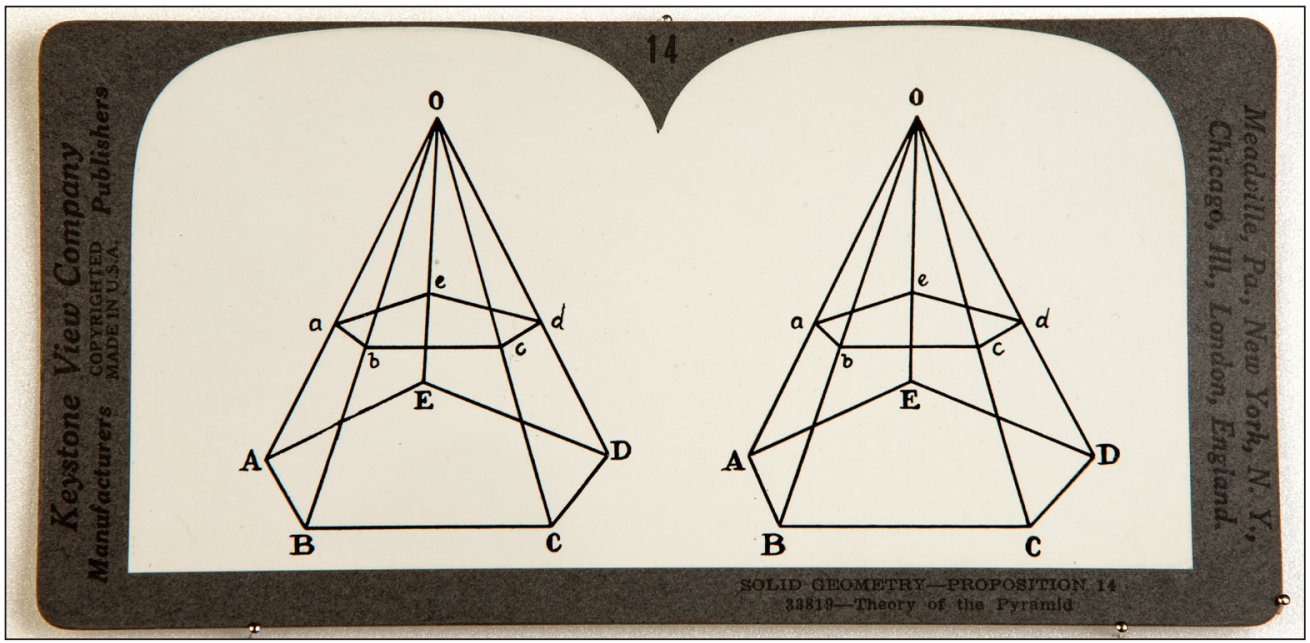

Figure 5 - Card 14. Designed and published by Keystone view, no date. Private collection.

Suppression is an important phenomenon in ophthalmologic practice. Sufferers of strabismus are unable to carry out stereopsis; that is, they cannot fuse the visual information coming from each eye. As a result, they "see double", they see what is before their eyes as two images side by side. However, the brain compensates for this uncomfortable phenomenon by suppressing the information given by one of the eyes, allowing only the information conveyed by the other eye to predominate and appear in the mind. In this way, suppression may give the 
impression that strabismic patients have carried out stereopsis, because they see a single (flat) image. Thus the responses by the strabismic patient, when examined without a stereoscope, will be identical to those of the healthy patient, for both will effectively see a single image:

The patient may obstinately affirm that he sees single and with both eyes, while he really sees with one eye, and neglects the image received by the other. The stereoscope furnishes an absolutely accurate test of the truth of the patient's assertions ${ }^{34}$.

A geometric solid, therefore, will elicit different answers from two patients, as one will see, for instance, only a triangle, where the other sees a pyramid.

Doctors were instructed to closely supervise the patients performing the stereoscopic exercises. Even in a collection meant for home exercises, the instructions recommended that the doctor should "read the directions with them [the patients] before they begin the training, and arrange for periodical check-up visits during the entire training period"35. A chart for marking the progress made was expected to be filled in by the patient doing the exercises at home, for the benefit of the doctor's control.

The stereoscopic exercise cards occupy a very peculiar position, as the exact same material played a role in both medicine and mass home entertainment ${ }^{36}$. The stereoscopic cards were operated in a context where subjectivity was made quantifiably determinable for the first time in the 19th century, after G. Fechner's experiments of 1860. The scientist then found ways of attributing quantitative features to perception ${ }^{37}$, thus analyzing human perception in terms of a sequence of magnitudes of varying intensities. The stereoscopic cards exist in a disciplinary context that "individualizes bodies by a location that does not give them a fixed position, but distributes them and circulates them in a network of relations" 38 . Jonathan Crary comments that Fechner's results relocated perception and the observer within the reach of empirical exactitude and technological intervention ${ }^{39}$. The scientist proposed a mathematical equation that expressed a functional relationship between sensation and stimulus. With such an equation, the inside/outside of the camera obscura, a paradigm challenged by the stereoscope, dissolves, and a new kind of annexation of the observer is possible.

The rationalization of sensation and the disciplining of the new binocular observer are explicitly present in the form of the exercises, and more loosely in the reshaping of the visual practices of an entire social field, through mass entertainment. Foucault proposed that homogenization is the key concept in 19th century human sciences; more so than quantification or mathematization:

In a sense, the power of normalization imposes homogeneity; but it individualizes by making it possible to erase gaps, to determine levels, to fix specialities, and to render the differences useful by fitting one to another. It is easy to understand how the power of the norm functions within a system of formal equality, since within homogeneity that is the rule, the norm introduces, as a useful imperative and as a result of measurement, all shading of individual differences ${ }^{40}$.
34. See Edmund Landolt, (1886, pp. 410-411)

35. See Anonymous (no date, p. 4)

36. This is literally the case with collections such as the Keystone Eye Comfort Series, where negatives from the company's archive, previously issued in the context of vistas from around the world, received additional ophthalmic graphic marks for diagnostic use, yielding the "hybrids" in question.

37. See Jonathan Crary, (1998, pp. 141-149)

38. See Michel Foulcault, (1995, p. 146)

39. See Jonathan Crary, (1998, p.145)

40. See Michel Foulcault, (1995, p. 184) 
41. See Octavio Paz, (1989, p. 152)

42. See Tim O'Riley, (1998, p.57)

43. See Octavio Paz, (1989, p. 157)

44. Ibidem, 153-154

45. See Jean Clair, (1978, p. 104)

46. See Penelope Haralambidou, (2013 p. 17)

47. See Tim O'Riley, (1998, p. 56)
Both patient and stereoscopic home consumer occupy a homogeneous field provided by the quantification or mathematization of perception. Both are observers who, through knowledge of the body and its modes of functioning, were being made compatible with new arrangements of power: the body as worker, student, pilot, patient, and criminal. The binocular perceiver was being rendered manageable, predictable, productive, and above all, consonant with other areas of rationalization-a crucial part of modernization-toward forms of power that depended on the abstraction and formalization of vision.

Duchamp and optics

Ocular movements and desires are also present in the work of Duchamp, an artist who has explored the artistic possibilities of stereoscopy. Duchamp's interest in optical phenomena, considered as a dimension of physical science or as an extreme of philosophical doubt, was precocious ${ }^{41}$. The artist was interested in perspective, but was ambivalent about it: as noted by Tom O'Riley, "the notes in the White Box referring to perspective and the fourth dimension suggest that Duchamp saw perspective as one type of representational method amongst others" 42 . This interest in stereoscopy took a more explicit form as the artist abandoned painting and embarked on activities that would culminate in the Large Glass, and ultimately in the Etant Donnés, within the wider field of his work that the artist himself called "Precision Optics."

The writer, Octavio Paz identified the centrality of the stereoscopic metaphor in Duchamp's oeuvre, especially in the works such as Large Glass and Etant Donnés: "But stereoscope is just another name of the elusive object that Duchamp sought for all his life" 43 .

Duchamp's interest in stereoscopy is further described by Paz:

The preoccupation with the relationship between the second and third dimensions led him, also from the beginning of his artistic activity, to an interest in stereoscopy. It was a passion that never left him [since his youth $]^{44}$.

Jean Clair concurs: for Duchamp, "the stereoscopic image showed the way to a purely ideal configuration, the intelligible result of a synthesis certainly closer to the brain-and to the working of a cosa mentale-than to the retinal effect" 45 . In the context of the artist's oeuvre, "anti-retinal" should not be confused with "anti-visual." Duchamp's active interest in optics attests to his interest in "visuality as an underlying structure of thought and creativity" 46 . For the artist, the creative act is not only sited in the work itself, but also in the "interaction between the work and the viewer, for it is through this exchange that the work becomes part of the world" 47 .

Duchamp developed a great interest in optics, and some of his work contemplates issues of the psychophysiology of vision. Explicitly stereoscopic pieces by Duchamp include the Stéréoscopie a la Main, a drawing titled Hieroglyphic 
Chimney, a 1920 film made in partnership with Man Ray (which was lost), and in a sense the installation Etant Donnés ${ }^{48}$. Rosalind Krauss emphasizes the following:

The whole of the Precision Optics that Duchamp went on to embrace-the Rotoreliefs and the Rotary Demisphere but also stereoscopy and anaglyphy [...]-all of this reaches back into the experimental and theoretical situation of the psychophysiology of vision ${ }^{49}$.

Author and architect, Penelope Haralambidou explored the stereoscopic features in Duchamp's work, highlighting the Etant Donnés. She states that both the Large Glass and Etant Donnés are renderings of the same program: both "stage the desirous gaze and analyze the act of looking. [...] However, the desire Duchamp stages in both his major pieces is not just erotic or sexual desire, but also a desire to see beyond the cultural construct of vision" 50 . The author selects the term "blossoming" to underline certain aspects of the artist's oeuvre, linking them to stereoscopy. "In Duchamp's work, the word blossoming signifies a transformation, a change in state: the passage from virgin to Bride, from three to four dimensions, the undressing of the Bride, and the explosion of desire"51. Furthermore, the term means "a vivid phenomenological effect combining intellectual and affective attributes, which cannot be directly represented by linear perspective or orthographic projection," 52 and is "analogous to the process of 'fusing' the two flat images of a stereoscopic pair into a virtual three-dimensional volume. The visual sensation can be described as an expansion from the plane of a single image into deep space, similar to the expansion of the petals from the center of the bud. So, stereoscopy also entails an épanovissement, a blossoming of the monocular picture plane, in the mind"53.

Etant Donnés is a mixed-media assemblage permanently installed in the Philadelphia Museum of Art, and was Duchamp's last work, executed in complete secrecy between the years 1946 and 1966, while it was thought that he had abandoned art for chess.

In contrast to the transparency of the Large Glass, Etant Donnés is a piece hidden behind closed doors. The abstract flat representation of the Bride captured within the infra-thin surface of the Large Glass is fully fleshed out in Etant Donnés, as a three-dimensional cast within the deep space of a brightly lit diorama ${ }^{54}$.

In Etant Donnés, the body of a woman, legs splayed, is seen through a breach in a brick wall, holding a gas lamp with her outstretched arm. The two peepholes that give visual access to the observer underline the fact that the viewer is
48. Etant donnés "is another example, bigger and better, of his interest in stereoscopy" (see Octavio Paz, 1989, pp. 153-154). In the same text (p. 157) Paz described the relation of Etant Donnés and the Large Glass as stereoscopic: "two images [of a woman in each piece], that fuse into one."

49. See Rosalind Krauss, (1993, p. 123)

50. See Penelope Haralambidou, (2007, p. 41)

51. Ibidem, pp. 42-43

52. Ibidem, p. 48

53. Ibidem, p. 43

54. Ibidem, p. 44

55. See Penelope Haralambidou, (2013, p. 13)

looking with both eyes, making the optical experience similar to looking into the illusory space of a stereoscope. Stereoscopy, a popular illusory technique infamously linked to pornography, transgresses perspective by isolating and revealing binocular depth and allowing an image to "blossom" in space. My analysis of Given [Etant Donnés] identifies stereoscopy as its central and intentional theme, influencing its intellectual content and guiding its manufacturing process ${ }^{55}$. 
56. Duchamp's Boîte-envalise, or box in a suitcase, is a portable miniature monograph enclosing sixtynine reproductions of the artist's own work, made mainly between 1935 and 1940. There were further editions and contents slightly vary.

57. See Octavio Paz, (1989, p. 26)

58. Ibidem, p. 21-24.

59. See Octavio Paz, (1989, p. 25-26)

60.See Rosalind Krauss, (1993, p. 96)

61. Ibidem, p. 137
Stéréoscopie a la main as a machine

Stéréoscopie a la Main is not one of Duchamp's better known pieces, and it has attracted relatively little critical attention. Though it was not possible to ascertain the exhibition life of the piece in question, Stéréoscopie a la Main was added to the Boite en Valise by the artist himself, which should stop us from discarding the piece without further thought ${ }^{56}$.

Stéréoscopie a la Main is a stereoscopic card for visualization in the "standard" stereoscope (the Holmes-Bates model). Duchamp's piece resembles certain stereoscopic cards used by ophthalmologists for ocular exercises and diagnosis of the conditions of binocular vision: both Stéréoscopie a la Main and the ophthalmologic cards bear a photograph, a vista of the exterior world, with added graphic marks. I suggest that the Stéréoscopie a la Main can also be seen as a basis for "stereoscopic exercises" of a very specific type.

The theoretical and experimental situation of psychophysiology mentioned above is intimately linked to Duchampian mechanisms. Octavio Paz described them as "contradictory machines" 57 . Machines feature prominently in the Large Glass and in other pieces by Duchamp, but not as figures of a futurist cult: "Machines are agents of destruction so the only mechanisms that spark Duchamp's passions are those that work in an unpredictable way-antimechanisms" 58 .

Furthermore:

The hilarious element doesn't make the machines more human but instead connects them with the center of man, with the source of its energy: indetermination, contradiction [...] contradictory machines $^{59}$.

Such is the case for the Rotoreliefs. They are machines in the physical sense too, as they rotate card discs for optical effects. The discs, as they turn, address the relationship of vision with desire. Krauss mentions authors who have made the case in point:

The effect of the turning through space, one of them says, is "an oscillating action of systole and diastole, screwing and unscrewing itself in an obsessional pulsation that could be associated to copulatory movements." And a second writer agrees that "the indication of the central cavity through the volutes of the spirals clearly evokes vaginal penetration. The fact that the eye by means of optical illusion perceives an in-and-out motion, establishes at an abstract level a literal allusion to the sexual act" 60 .

Furthermore, she adds the following:

It is in that languidly unreeling pulsation, that hypnotically erotic, visual throb of Duchamp's Precision Optics, that one encounters the body of physiological optics' seeing fully enmeshed in the temporal dimension of nervous life ${ }^{61}$. 
Eroticism in Duchamp's work is also connected with "an architecture of looking, and both the Large Glass and Etant Donnés are 'bachelor' machines for looking at the coveted image on an unattainable 'Bride'." Duchamp arranges the constituent parts of these optical machines to form complex spatial constructs ${ }^{62}$.

Stéréoscopie a la Main, in its turn, is a pair of stereoscopic photographs mounted on card. Over each photograph, two pencil-drawn inverted pyramids form a single geometric solid, something like a wire-frame diamond. When viewed in the Holmes-Bates stereoscope, the image gains relief: the sea recedes into the background and the geometric solid detaches from the plane. Duchamp constructed this "rectified ready-made" when he was in Buenos Aires in 1918.

How can we understand Stéréoscopie a la Main within this context of machines linked to desire? It lacks the explicit throb of the Rotoreliefs, but I contend that it is also a kind of mechanism of desire nevertheless. The gyrating discs engage the eye in what we can only call a "passive" manner, i.e., the engagement of the eyes occurs in a different way than for stereoscopic viewing: there is no refocusing or meandering of the "phantom limb." The operation in question involves relaxing in front of the device and letting the revolving drawings operate their "illusion" in the observer.

However, in stereoscopic viewing, a bigger effort is demanded of the observer; a kind of engagement we can call "active." The spectator becomes "both producer and consumer of the illusion. As Crary notes, the stereoscopic "image" itself does not exist "out there" in a tangible way. For him, it is more of a "conjuration, an effect of the observer's experience, of the differential between two other images"63. This is quite explicit in the "stereoscopic exercise," where the repetitive binocular movements are necessary in order to generate a climax, i.e., the perfect convergence of the two eyes and the ensuing generation of stable stereoscopic space and volume - the "deep channel of space" that opens up before the observer, the Duchampian "blossoming."

Stéréoscopie a la Main can be thought of as piece in the realm of "metaphorical analogues to or replacements for human organisms"64, and, as in the Large Glass, Duchamp had found "a 'mechanistic' language to be the appropriate vehicle for this exploration of sexual interaction"65. One can think of the Stéréoscopie a la Main as a human-machine hybrid, an ocular mechanism sparked by the desiring gaze of the observer, who strains the eyesight toward a "blossoming."

In this sense, Stéréoscopie a la Main indeed relates to the Large Glass, which is one of Duchamp's greatest and most profound works. Clair proposes that both pieces hold a relationship of reversibility 60 . Etant Donnés also named The Bride Stripped Bare by Her Bachelors, and even, the Large Glass was made from 1915 to 1923. It is composed of two panes of glass, and the materials employed include lead foil, fuse wire, paint, and dust, extending to just under nine feet high and five and a half feet wide. The Green Box is a companion to the Glass, containing notes related to this work, published with the intention of complementing the visual experience, so as to prevent purely visual responses to it. Duchamp once called the
62. See Penelope Haralambidou, (2013, p. 10)

63. See Tim O'Riley, (1998, p. 60) and Jonathan Crary, (1990, p. 122)

64. Linda Dalrimple Henderson, (1998, p. 34)

65. Ibidem, p. 173

66. See Jean Clair, (1978, p. 108) 
67. See Octavio Paz, (1989, 90)

68. See Tim O'Riley, (1998, p. 60)
Large Glass a "hilarious picture" that is intended to depict the erotic encounter between a bride and her nine bachelors, which is observed by the Oculist Witnesses. Octavio Paz states that "[Stéréoscopie a la Main] holds an undoubted and intimate relationship with the Oculist Witnesses"67.

In the Large Glass, the enigmatic bride and bachelors are placed in two separate sections of the piece, but, nonetheless, are engaged in erotic exchanges. The whole affair is observed by the Oculist Witnesses. These are formed by patterns taken out of oculists' charts including, for instance, the Astigmatic Clock. The circular patterns are seen in perspective. I wish to underline the fact that such graphic marks are not used for diagnosis only, but that they are also the basis for ocular exercises, as is the case with the Astigmatic Clock. That is, these circular drawings serve not only for passive gazing (as in the identification of letters, for instance), but also for active gazing along the drawn lines. It is possible to correct astigmatism by looking intently at the Clock and deliberately following the lines in a prescribed order. Furthermore, it is possible to say that the Oculist Witnesses are, in the context of the Large Glass, actively engaged in ocular movements in a context of voyeuristic desire and onanism, as they perform their role in the piece.

Thus, ophthalmic elements linked to active ocular movement in the context of desire are to be found in other pieces by Duchamp, explicitly in the Large Glass and Etant Donnés, and implicitly in the Rotoreliefs; and the first of the works keeps an intimate link with Stéréoscopie a la Main. In this way, the similarity between the stereoscopic cards used by ophthalmologists and the Stéréoscopie a la Main suggest that this piece by Duchamp can be seen in the context of a kind of gymnastics associated to the sexual drive, or to onanism. It represents a trajectory for the eye drawn in the three-dimensional space of the stereoscopic image aimed at erotic movements; a device for the haptic exercise of desire. Stéréoscopie a la Main seems to offer the viewer lines along which the gaze may glide, a machine-like circuit that is activated by the desiring roving eye.

Is Stéréoscopie a la Main really stereoscopic?

One has to confront the issue that this piece's stereoscopic effect is weak when compared to standard stereographs: "Duchamp's Stéréoscopie à la main is perhaps untypical of a large proportion of Victorian cards in that when viewed appropriately, the experience of depth is unremarkable." 68 . Indeed, Tim O'Riley maintains that the wireframe figure is resolutely "flat." Duchamp does not seem to have left any clues about the piece, and the title alone does not allow us to state that its two components - the seascape and the drawn octahedron-are both meant to be stereoscopic. O'Riley's point is that only the seascape is stereoscopically constructed, but no volume or depth is featured in the figure itself, which just sits apart from the sea, flatly so, with no volume of its own. I believe that one may dispute the lack of stereoscopic effect in the wireframe figure and state that there is a visual "blossoming" of stereoscopic nature, albeit weak. One must bear 
in mind that the borders of stereo perception are mobile. Different people have different binocular capacities and will perceive and interpret depth information differently. So, the best way to establish the presence or absence of stereoscopic effect is to look for horizontal disparities in the drawing, perhaps by overlapping the two sides of the card in Photoshop. In this way, the necessary horizontal disparity seems visible, though indeed it is not consistent in the sense of producing a crisp stereoscopic geometric solid, yielding instead an imperfectly constructed stereoscopic figure.

The fact remains that at least the background features a stereoscopic effect, and that both figure and seascape are separated by a space constructed stereoscopically. Thus, all stereoscopic analogies for Stéréoscopie a la Main and related works still hold. Even if the wireframe solid features no stereoscopic effect at all, it is still to Duchamp's credit to have created a stereoscopic environment where a Necker-like figure titillates and stimulates the eyes of the beholder.

Conclusion

As has been demonstrated, Duchamp had a life-long interest in stereoscopy that overlapped with his use of ophthalmologic materials, such as oculists' charts. But did he discover the highlighted stereoscopic ophthalmologic materials directly? Was he aware of the stereoscopic exercises, as practiced in medicine? He may well have been, as at least some of these materials were also published by large stereoscopic companies for home use, and were presumably available in the stereoscopic market at large. Nevertheless, there is no hard evidence that Duchamp was aware of the ophthalmic stereoscopic exercises themselves.

One can imagine, however, how the artist might have used the ophthalmic exercises, subverting their procedures in the context of erotic machines: machines which he could use to contradict the docile able body; to disturb their infinitesimal power over individual bodies.

He may have insisted on evading of the authority of the doctor, who should preside over the application of the stereoscopic exercises, at the very least carefully guiding and checking the progress made by the patient. Duchamp could have dispensed with these instructions entirely, anarchically taking the viewers' eyes for an unchaperoned free ride around the landscape of Stéréoscopie a la Main.

Or perhaps he aimed to sabotage the precise recording of performance progress. The exercises, performed at home or at the doctor's consulting room, were to be carefully recorded in the appropriate tables in a booklet accompanying the images. If the notes gathered in the Green Box are intended to serve as "explanations" to the Large Glass, Duchamp's written records regarding progress in the stereoscopic exercises would feature numerous puns, omissions, contradictions, wordplay, oblique references, and plenty of unfinished business: Duchamp's work exemplifies the "paradox of constructing rules combined with the desire to break them" 69 .
69. Penelope Haralambidou, (2013, p. 13) 
70. See Michel Foucault, (1995, p. 137)

71. See Manual of Instructions... (No date, p. 21)
From a Foulcaultian perspective, Duchamp would have been resisting the increasing standardization and regulation of the observer that issued from the knowledge of a viewing body, toward forms of power that depended on the abstraction and formalization of vision. A rebel patient, inhabiting his own strange machine that forces anti-homogenizing practices, seeking to find or produce fissures in the field of equality built by stereoscopic exercises, both ophthalmic and of the "home travel" type, thus stoking the fire of desire present in ocular movements. He would be resisting normalization as he re-routed the energy usually spent in the disciplining of vision toward an erotics of viewing, challenging discipline as being methods "which made possible the meticulous control of operations of the body, which assured the constant subjection of its forces and imposed upon them a relation of docility-utility"70.

\section{Coda: Graphing erotic stereoscopic exercises}

As a visual Coda for the text, a Duchampian exercise was carried out. I have "rectified" a stereoscopic card for ophthalmologic use from the Keystone View EyeComfort Series along Duchampian lines, as shown in the sequence of Figures 6 to 7.

This particular card for stereoscopic exercises, here placed below Stéréoscopie a la Main, features numbered positions placed over a scenic landscape. The numbered positions work as departure and arrival points for the prescribed itinerary of the gaze. The patient must guide the gaze from number to number according to the prescription of the given exercise. The lines followed by the gaze, here marked out in black by the author of this text, indicate the path to be followed. The resulting lines (three itineraries prescribed in Exercise 8 of Step 6 in the Manual of Instructions for the Zeta Eye-Comfort Unit of the Keystone Eye-Comfort Series to be used in the Keystone Eye-Comfort Stereoscope ${ }^{71}$ form a geometric figure.

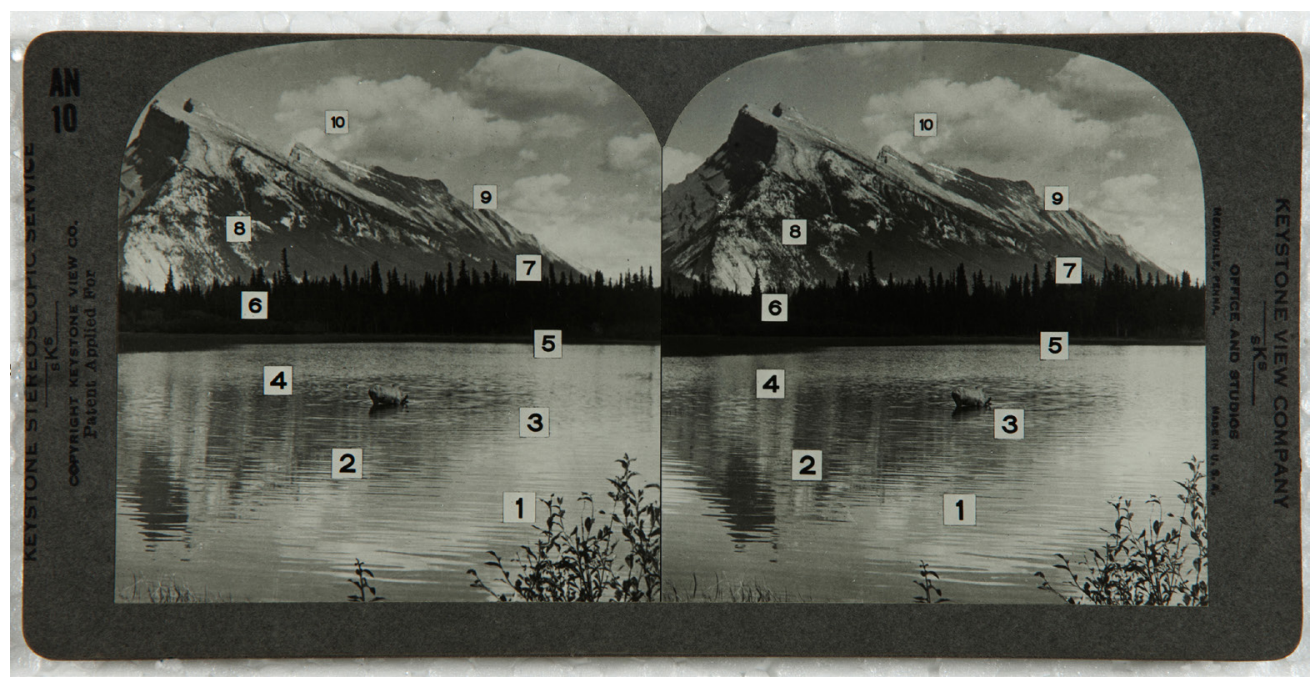

Figure 6 - Card AN 10. Stereoscopic card from the Eye Comfort Series, published by Keystone View, no date. Private Collection. 


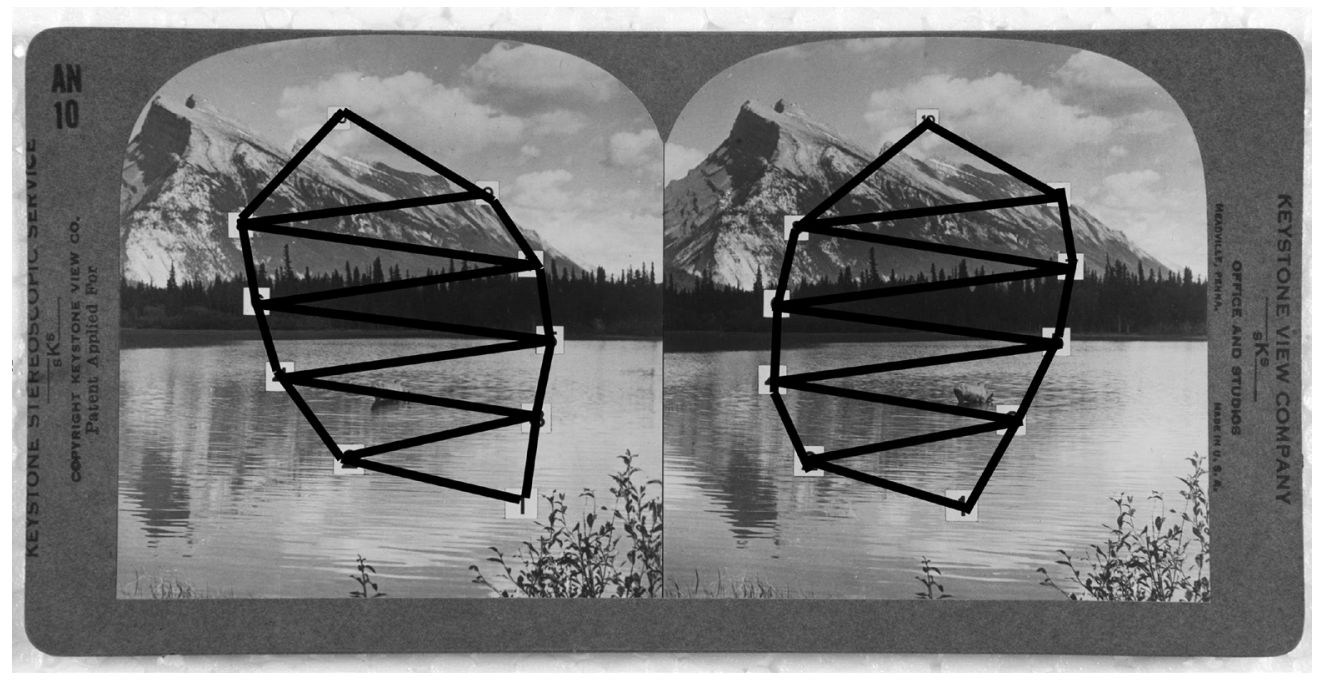

Figure 7 - Rectified Keystone card, stereoscopic card with added graphic marks by Gavin Adams, 2014. Private collection.

As I emulate Duchamp, "rectifying" a stereoscopic card, penciling in the path followed by the gaze according to clinical instructions of the ophthalmologic manual, I want to visually suggest that the geometric solid of Stéréoscopie a la Main can also be seen as a basis for a kind of stereoscopic exercise, a stereo-erotic exercise. 


\section{REFERÊENCIAS}

ALTICK, Richard. The Shows of London. Cambridge: Belknap Press, 1978.

BATCHEN, Geoffrey. Enslaved Sovereign, Observed Spectator: on Jonathan Crary, Techniques of the Observer. Continuum: Journal of Media \& Cultural Studies, Abingdon, v. 6, n. 2, p. 8094, 1993.

BROWN, Karen Beth. From Travel to Tourism: the Relation of Photography to Social Change in Nineteenth-century America. 1992. Dissertation, 158 p. (PhD) - New York University, New York, 1992.

CLAIR, Jean. Opticeries. October, Cambridge, n. 5, p. 101-112, 1978. Photography.

CRARY, Jonathan. Techniques of the Observer. Cambridge: MIT Press, 1998.

DARRAH, William Culp. The World of Stereographs. Gettysburg: Darrah, 1977.

DELESKIE, R. The Underwood Stereograph Travel System: a Historical and Cultural Analysis. 2000. Dissertation, 194 p. (PhD) - Concordia University of Montreal, Quebec, Canada, 2000

DULLES, Foster Rhea. Americans Abroad: Two Centuries of European Travel. Ann Arbor: University of Michigan Press, 1964.

FOUCAUlT, Michel; SHERIDAN, Alan. Discipline and Punish. New York: Random House, 1995.

FOWLES, Jib. Stereography and the Standardization of Vision. Journal of American Culture, Bowling Green, v. 17, n. 12, p. 89-93, 1994.

HARALAMBIDOU, Penelope. Marcel Duchamp and the Architecture of Desire. Farnham: Ashgate Publishing, 2013.

HARAlAmBIDOU, Penelope. The Stereoscopic Veil. Arq: Architectural Research Quarterly, Cambridge, v. 11, n. 1, p. 37-51, 2007.

HELMHOLTZ, Hermann von. Popular Lectures on Scientific Subjects. New York: Appleton \& Company, 1885

HENDERSON, Linda Dalrymple. Duchamp in Context: Science and Technology in the Large Glass and Related Works. Princeton: Princeton University Press, 1998.

HOLMES, Oliver Wendell. Soundings from the Atlantic. Boston: Ticknor and Fields, 1864.

KRAUSS, Rosalynd. The Optical Unconscious. Cambridge: MIT Press, 1993.

KRAUSS, Rosalynd. Photography's Discursive Spaces: Landscape - View. The Art Journal, London, v. 42, n. 4, p. 311-319, 1982.

LANDOLT, Edmund. The Refraction and Accommodation of the Eye and their Anomalies. Edinburgh: Pentland, 1886. 
MANUAL of Instructions for the Zeta Eye-Comfort Unit of the Keystone Eye-Comfort Series to be Used in the Keystone Eye-Comfort Stereoscope. Meadville: Keystone View Company, c1943.

O’RILEY, Timothy. Representing Illusions: Space, Narrative and the Spectator. 1998. Thesis, 157 p. (PhD) - Chelsea College of Art \& Design, London, 1998.

OSBORNE, Peter. Travelling Light: Photography, Travel and Visual Culture. Manchester: Manchester University Press, 2000.

OSBORNE, Albert. The Stereograph and the Stereoscope with Special Maps and Books Forming a Travel System; What They Mean for Individual Development, What They Promise for the Spread of Civilization. New York: Underwood and Underwood, 1909.

PAZ, Octavio. Apariencia desnuda: la obra de Marcel Duchamp. Madrid: Alianza Editorial, 1989.

PELLERIN, Denis. File BB3 and the Erotic Image in the Second Empire. In: REYNAUT, Françoise et al. Paris in 3D: From Stereoscopy to Virtual Reality 1850-2000. Paris: BoothClibborn Editions, 2000. p. 91-99.

RAYFIELD, Beth. Double Dating: Courtship Ritual and the Radical Potential of Stereographic Viewing. Iconomania: Studies in Visual Culture, Los Angeles, 1998. Disponível em: <http:// www.humnet.ucla.edu/humnet/arthist/Icono/rayfield/dbldate.htm>. Acessed in April 2006:

RUBIN, Joan Shelley. The Making of Middle Brow Culture. Chapel Hill: University of North Carolina Press, 1992.

WELLS, David Washburn. Stereoscopic Treatment of Heterophoria and Heterotropia. New York: EB Meyrowitz, 1912.

Artigo apresentado em 09/06/2015. Aprovado em $31 / 08 / 2015$. 